\title{
A STUDY OF THE GROUPED ARRANGEMENTS OF STUD CONNECTORS ON SHEAR STRENGTH BEHAVIOR
}

\author{
Jun OKADA ${ }^{1}$, Teruhiko YODA ${ }^{2}$ and Jean-Paul LEBET ${ }^{3}$ \\ ${ }^{1}$ Member of JSCE, Senior Researcher, Civil Engineering Dept., JFE R\&D Corporation \\ (1-1 Minamiwatarida-cho, Kawasaki-ku, Kawasaki, 210-0855, Japan) \\ E-mail: j-okada@jfe-rd.co.jp \\ ${ }^{2}$ Fellow of JSCE, Professor, Civil and Environmental Eng. Dept., Waseda Univ. \\ (3-4-1 Okubo, Shinjuku-ku, Tokyo, 169-8555, Japan) \\ E-mail: yoda1914@waseda.jp \\ ${ }^{3}$ Lecturer, ICOM GC, École Polytechnique Fédérale de Lausanne (EPFL) \\ (ICOM GC B3 475 Station 18, CH-1015, Lausanne, Switzerland) \\ E-mail: jean-paul.lebet@epfl.ch
}

\begin{abstract}
Firstly, failure mode and shear strength of stud connectors were investigated based on push-out test results. Secondly, the practicability of a proposed analytical method was verified on the basis of a comparison with test results and the failure mechanism of the grouped arrangement was investigated. Lastly, parametric analyses on concrete strength and on the longitudinal spacing of stud connectors were conducted and shear strength reduction equations of the grouped arrangement of stud connectors were proposed.
\end{abstract}

Key Words : push-out test, stud connector, grouped arrangement, shear strength

\section{INTRODUCTION}

Recently, many studies on steel-concrete composite structures have been done owing to the need for rationalization and cost reduction. A typical example of the connection method between steel and concrete is using headed stud connectors (referred to below as studs). Because of their strength and usability, studs are widely used ${ }^{1)}$ in the various types of structures.

However, when studs are applied to the connection between the steel girder and the shear holes of precast slabs, to the connection between the main girders and the piers, as well as to the connection between the steel cells of the pier and the covering concrete, the studs are often arranged longitudinally and transversally with smaller spacing between each stud (This is referred to hereafter as the 'grouped arrangement'.). If the studs are grouped very closely together in the connection, the required performance may not be satisfied.

According to the Japanese Design Specifications ${ }^{2)}$ or Eurocode $4^{3)}$ etc., the design shear strength of studs is based on standard push-out tests where the studs are arranged in fully larger spacing (This is referred to hereafter as the 'standard arrangement'.). Therefore, whether or not the strength of the grouped arrangement of studs equals the sum of the strength of the standard arrangement of studs has not yet been clarified.

Investigations on grouped arrangement of studs can be classified into two groups. One concerns the behavior of composite girders which have connections between the steel girder and the shear holes of the precast slabs. The other concerns the shear strength of a grouped arrangement of studs where the longitudinal center to center spacing of each stud is less than $5 d$ ( $d$ is a diameter of the shank of the stud).

Regarding the behavior of composite girders, it is concluded from various tests and analyses that no obvious difference is found between the standard arrangement and the grouped arrangement in deformation distribution and in a longitudinal slip even if creep, shrinkage, and thermal effects along with the dead load and the live load are considered ${ }^{4)}$-7).

On the other hand, studies on the shear strength of the grouped arrangement of studs are mainly based on the push-out tests. The authors carried out push-out tests at EPFL in Switzerland ${ }^{8)-11)}$. Later Okubo et al. did push-out tests ${ }^{12)}$ using the same parameters of test specimens as the authors did. It is recognized from these tests that no obvious reduction in shear strength can be found if the size of the 

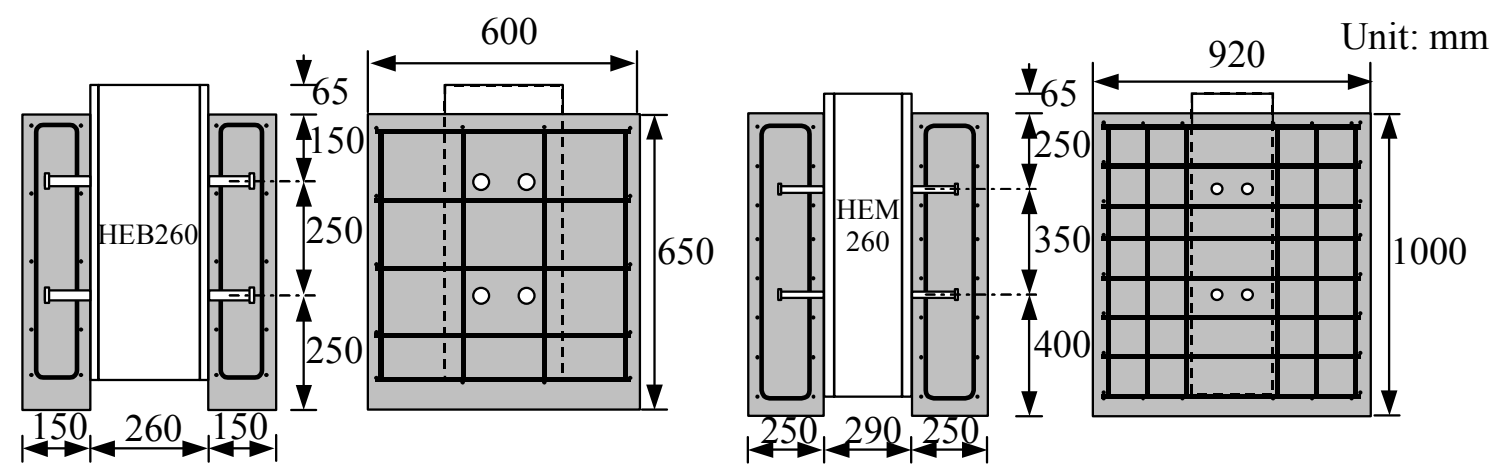

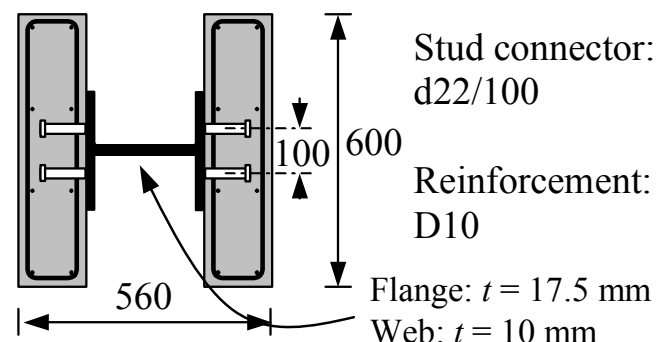

(a) SP1

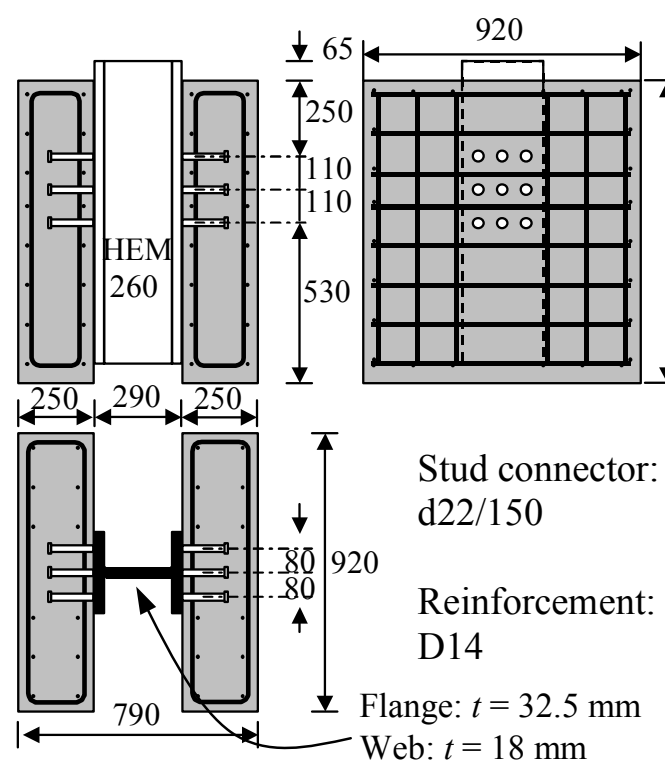

(c) SP3

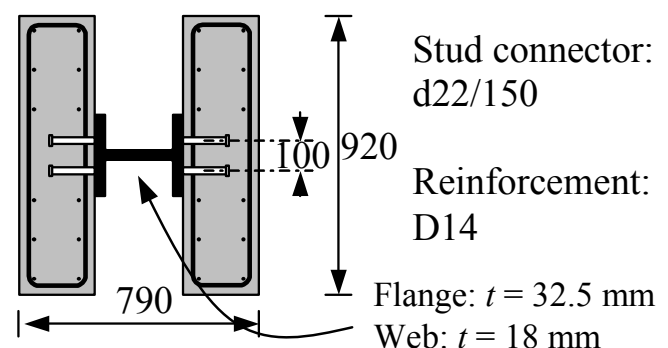

(b) SP2
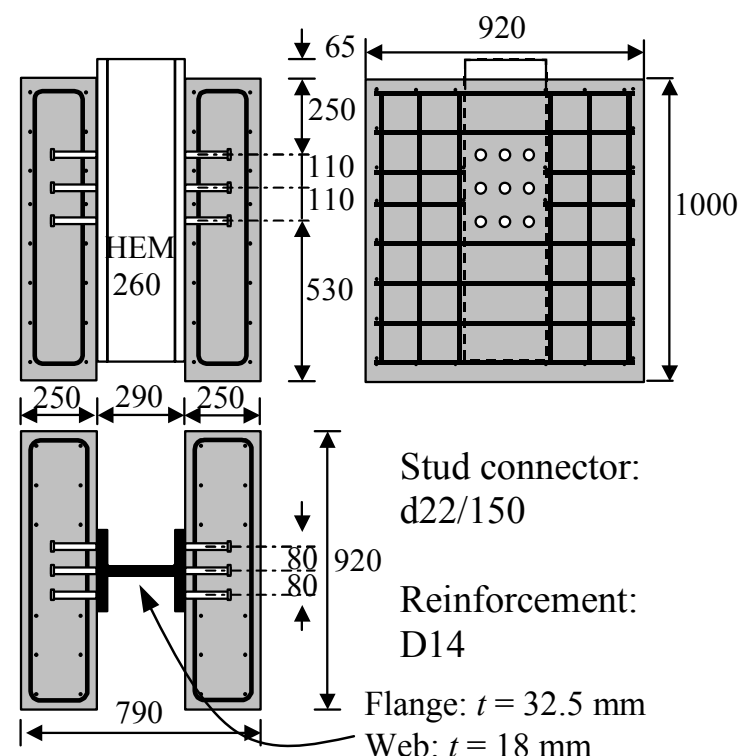

(d) SP4

Fig.1 Test Specimens

specimens, the content of reinforcement, and the strength of concrete are sufficient. Some investigators indicate, however, depending on the experimental parameters, that a possible reduction in shear strength may be induced due to the high concentrated forces in the grouped arrangement ${ }^{13), 14)}$. Accordingly, test results lack consistency.

Following from the above situation, in order to apply the grouped arrangement of studs to the shear holes of precast slabs, to the connection between the main girders and the piers, and to the connection between the steel cells of the pier and the covering concrete, first, failure mode and shear strength of the studs were investigated based on push-out tests where relatively high strength concrete and reinforcement were used. Secondly, the practicability of the proposed analytical method was verified on the basis of a comparison with the test results and further, the failure mechanism of the grouped arrangement was investigated. Lastly, parametric analyses on concrete strength and on the longitudinal spacing of studs were conducted and shear strength reduction equations of the grouped arrangement of studs were proposed.

\section{PUSH-OUT TESTS}

\section{(1) Specimens and test procedures}

The four types of the specimens used in this study are shown in Fig. 1. SP1 is the Eurocode 4 standard specimen with a standard arrangement of studs. SP2 


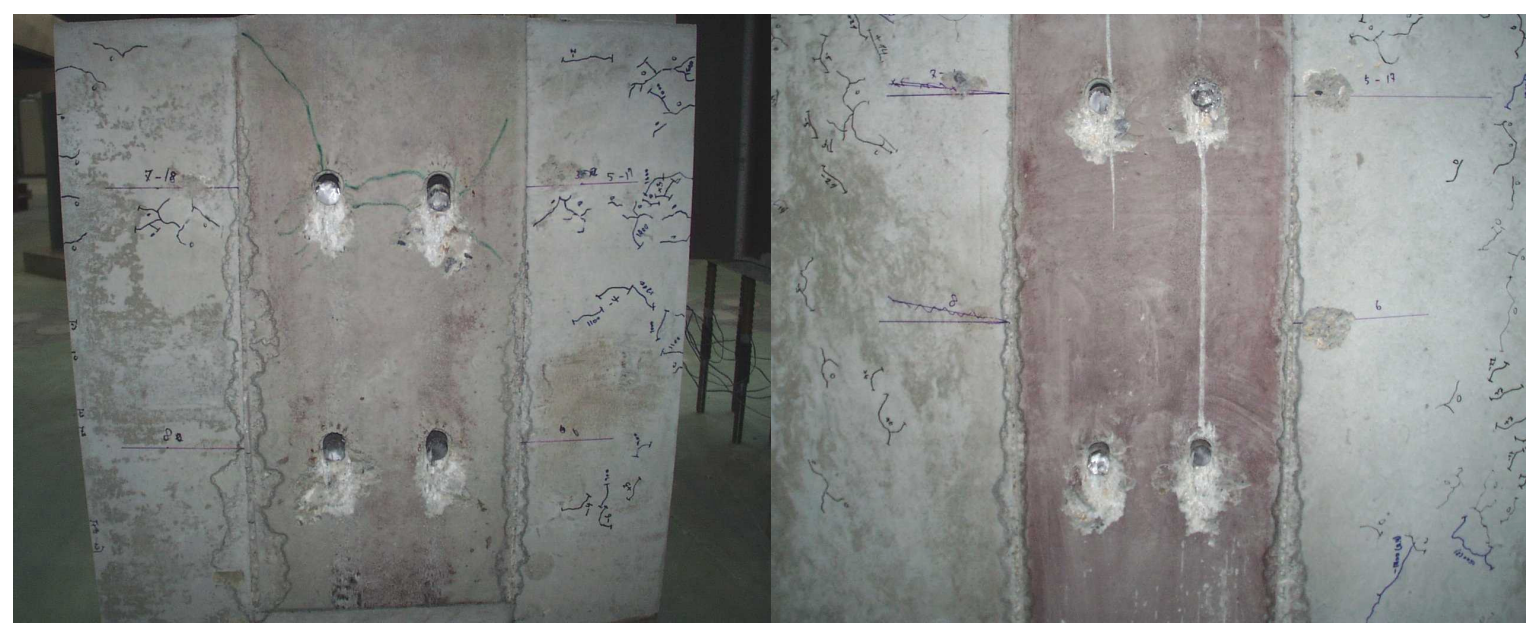

(a) SP1

(b) SP2

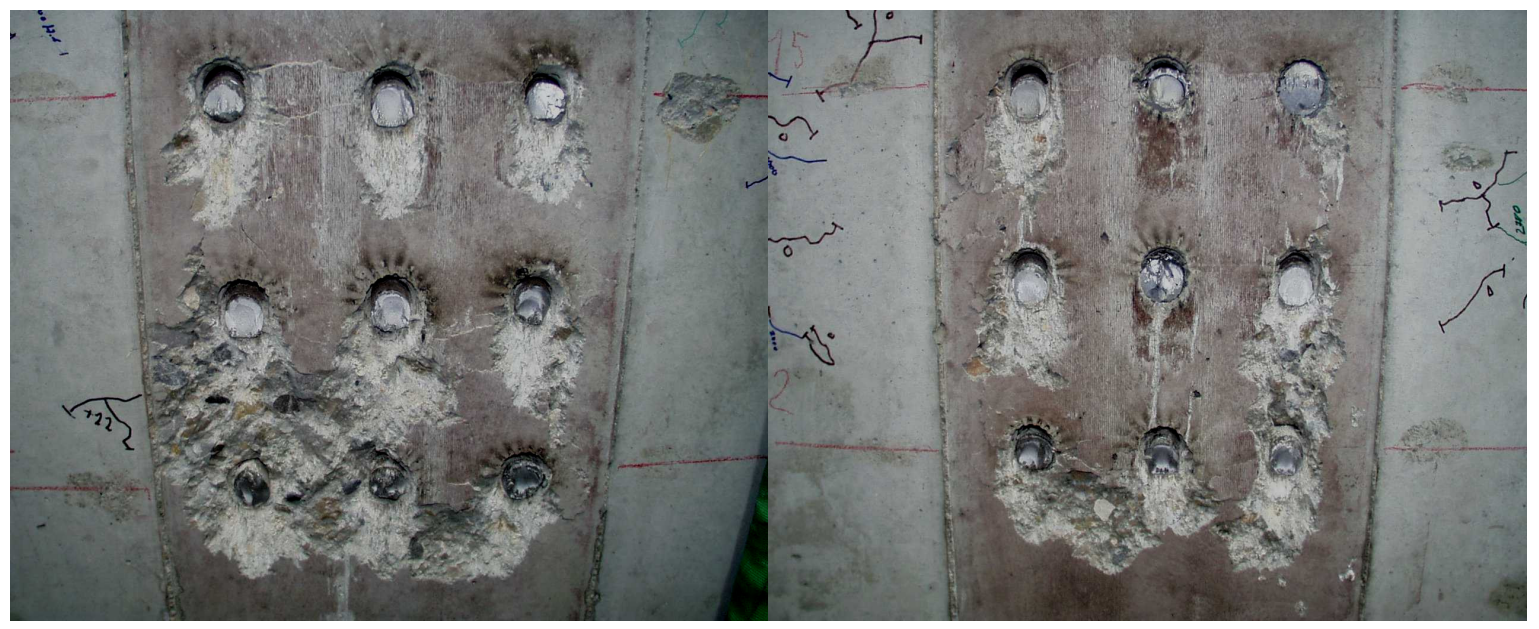

(c) $\mathrm{SP} 3$

(d) SP4

Fig.2 Failure mode

is designed to investigate the different sizes of specimens between small specimens (SP1) and large specimens (SP3 and SP4). Accordingly, SP2 is provided with the standard arrangement and the same number of studs as SP1, but the length of the studs, the size of the steel beam, and the size of the concrete slabs are identical to SP3 or SP4. SP3 is the grouped arrangement specimens provided with 9 studs in each concrete slab. SP4 is identical to SP3 except that all the transverse reinforcement is placed on the outside of the grouped studs. This is intended for simplification of construction at the site.

The specimens are designed according to the requirement of Eurocode 4. Studs; FeE235D (design yield strength $f_{\text {ystd }}=350 \mathrm{~N} / \mathrm{mm}^{2}$, design ultimate strength $f_{\text {ustd }}=450 \mathrm{~N} / \mathrm{mm}^{2}$ ) and reinforcement; S500a (design yield strength $f_{y s d}=460 \mathrm{~N} / \mathrm{mm}^{2}$, design ultimate strength $f_{\text {usd }}=550 \mathrm{~N} / \mathrm{mm}^{2}$ ), which are typical in Switzerland, are used. The size of the slabs, the content of reinforcement, and the design compressive strength of concrete $\left(f_{c d}=35 \mathrm{~N} / \mathrm{mm}^{2}\right)$ were set so that the design strength of the slabs to longitudinal shear might be greater than the design shear strength of studs. This means that failure mode of these specimens is assumed not to be 'failure of concrete' but to be 'shear failure of the studs'. For the design of longitudinal spacing of studs in a grouped arrangement, five times the diameter of the shank of the stud $(5 d=110 \mathrm{~mm})$, which is the minimum value in Eurocode 4, is adopted. On the other hand, transverse spacing of studs, $3.6 \mathrm{~d}$, is adopted from an actual bridge in Switzerland making allowance for execution of grouped arrangement at the site.

Three identical specimens for each kind were prepared. In the notation of the specimens, the first number distinguishes the kinds of specimens and the second number, after a dash, indicates three identical specimens, for example, SP1-1, SP1-2, SP1-3. The specimens were concreted at three different times, namely, SET1: SP1-1, SP2-1, SP3-1, SP4-1, SET2: SP1-2, SP2-2, SP3-2, SP4-2, and SET3: SP1-3, SP2-3, SP3-3, SP4-3. The concrete was cast when the specimens were placed in the vertical position. The compressive strength of concrete was deter- 
mined from standard cylinder tests. The average value of this in SET1, SET2, and SET3 was 49.5 $\mathrm{N} / \mathrm{mm}^{2}, 44.3 \mathrm{~N} / \mathrm{mm}^{2}$, and $49.4 \mathrm{~N} / \mathrm{mm}^{2}$, respectively.

Initially, load was cycled 25 times between $5 \%$ and $40 \%$ of the expected failure load according to the requirement of Eurocode 4. Then, load was applied until the failure of the specimens was obviously recognized. The initial loading speed was 12 to 20 $\mathrm{min} / \mathrm{mm}$ of displacement. It was increased to a maximum of $5 \mathrm{~min} / \mathrm{mm}$ corresponding to the reduction of rigidity of the specimens.

\section{(2) Test results}

\section{a) Failure mode}

All of the specimens failed due to shear of the studs. Typical failure mode of each kind of specimen at the concrete surface is shown in Fig. 2. Meaningful difference in local failure surface of concrete is seen between the standard arrangement and the grouped arrangement of studs. SP1 and SP2, the standard arrangement specimens, show that the local failure surface of concrete around each stud is independent of each other. On the other hand, SP3 and SP4, the grouped arrangement specimens, show that some of the local failure surfaces of concrete link together. For the purpose of investigating the failure mode more deeply, specimens were cut longitudinally in the middle of the studs. Failure mode at the cutting surface of the specimens is shown in Fig. 3.

Fig. 3(a) illustrates typical cracks in the standard arrangement specimens. Two types of cracks were found in the arrangement. Type (a) cracks started from the head of studs. This would happen as a result of the bending stress acting on the studs. Type (b) cracks happened at the compressive stress zone immediately in front of the lower portion of the studs. This would happen as a result of the combination of the compressive stress and shear stress.

Fig. 3(b) illustrates typical cracks in the grouped arrangement specimens. It is significantly different from the case of the standard arrangement that Type (b) cracks extend to the next stud. This mode is probably unique to the grouped arrangement of studs. If such failure modes were significant, the influence of grouped arrangement on the shear strength could be greater.

\section{b) Shear strength}

Table 1 presents the maximum shear strength per stud, the dropping rate of the maximum shear strength to SP1, and the longitudinal slip at the maximum shear strength, respectively. The test result of SP2-1 was excluded from the evaluation because SP2-1 was poorly concreted. The followings are derived from the test results: loading direction

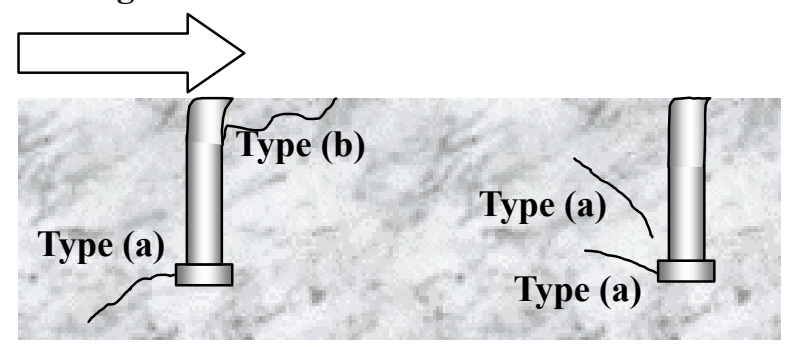

(a) Standard arrangement

\section{loading direction}

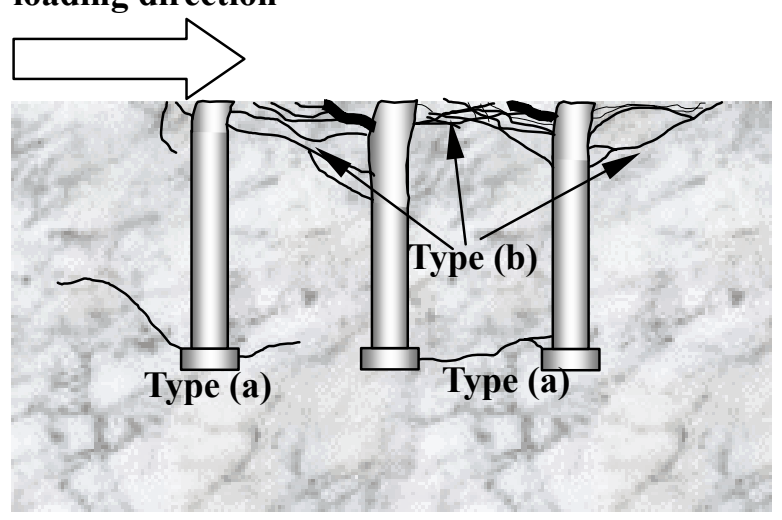

(b) Grouped arrangement

Fig.3 Failure mode at the cutting surface

Table 1 Push-out test results

\begin{tabular}{|c|c|c|c|c|}
\hline & & $\begin{array}{l}\text { Maximum } \\
\text { shear } \\
\text { strength } \\
(\mathrm{kN} / \mathrm{stud})\end{array}$ & $\begin{array}{c}\begin{array}{c}\text { Dropping } \\
\text { rate* }\end{array} \\
(\%) \\
\end{array}$ & $\begin{array}{c}\text { Maximum } \\
\text { slip** } \\
(\mathrm{mm}) \\
\end{array}$ \\
\hline \multirow{4}{*}{ SP1 } & SP1-1 & 229 & 0 & 6.4 \\
\hline & SP1-2 & 198 & 0 & 8.3 \\
\hline & SP1-3 & 210 & 0 & 12.0 \\
\hline & Ave. & 212 & $\mathbf{0}$ & 8.9 \\
\hline \multirow{4}{*}{ SP2 } & SP2-1 & ---- & ---- & ---- \\
\hline & SP2-2 & 196 & 1 & 8.9 \\
\hline & SP2-3 & 207 & 1 & 5.2 \\
\hline & Ave. ${ }^{* * *}$ & 202 & 1 & 7.0 \\
\hline \multirow{4}{*}{ SP3 } & SP3-1 & 208 & 9 & 5.6 \\
\hline & SP3-2 & 192 & 3 & 6.3 \\
\hline & SP3-3 & 201 & 4 & 5.5 \\
\hline & Ave. & 200 & 5 & 5.8 \\
\hline \multirow{4}{*}{ SP4 } & SP4-1 & 205 & 10 & 5.8 \\
\hline & SP4-2 & 190 & 4 & 7.4 \\
\hline & SP4-3 & 208 & 1 & 6.1 \\
\hline & Ave. & 201 & 5 & 6.4 \\
\hline \multicolumn{5}{|c|}{ Dropping rate of the maximum shear strength to SP1. } \\
\hline$* *$ & gitudinal & ip at the max & num shear & ength. \\
\hline
\end{tabular}

1) The maximum shear strength of the grouped arrangement (SP3 and SP4) is about 5\% lower than that of SP1 and $3-4 \%$ lower than that of the standard arrangement (SP1 and SP2) on the av- 
erage. Therefore, the influence of the grouped arrangement is small enough to be negligible. However, if a lower compressive strength of concrete were used, this influence could be greater.

2) The longitudinal slip at the maximum shear strength of the grouped arrangement specimens is about $25 \%$ smaller than that of the standard arrangement specimens.

3) No obvious influence of the different arrangement of reinforcement was observed between SP3 and SP4.

\section{ANALYTICAL VERIFICATION OF THE PUSH-OUT TESTS}

3-dimensional FE-analysis was performed focusing on the grouped arrangement specimens (SP3 and SP4). A general-purpose finite element package, DIANA ${ }^{15}$, is used for the analysis. SP3 and SP4 are selected for the target for the following reasons:

1) Detailed test results are obtained.

2) The specimens are designed according to the requirement of Eurocode 4. The sufficiency of the size of the slabs and the content of reinforcement is satisfied. The steel beam is thick and rigid so that it would not buckle or yield to the shear force from the grouped arrangement of studs.

3) The size of the studs is typical; $d=22 \mathrm{~mm}$, length $L=150 \mathrm{~mm}(L / d=6.8)$

\section{(1) FE-model}

An FE-model ${ }^{16)}$ is shown in Fig. 4. 1/4 of the SP3 or SP4 specimens are modeled with the symmetrical conditions. The concrete slab, the studs, and the flange of the steel beam are modeled by solid elements. The web of the steel beam is modeled by shell elements. The reinforcements (not shown in the Figure) are modeled by bar reinforcement elements, which assume a perfect bond between the reinforcements and the surrounding concrete. To allow for slip and to apply the discrete crack model and the bond-friction model, which will be described later, interface elements are used between the steel beam and the concrete surface and between the studs and the concrete surfaces.

\section{(2) Material models}

\section{a) Concrete}

Compressive strength $f_{c}$, tensile strength $f_{t}$, Yong's modulus $E_{c m}$, which were determined from standard

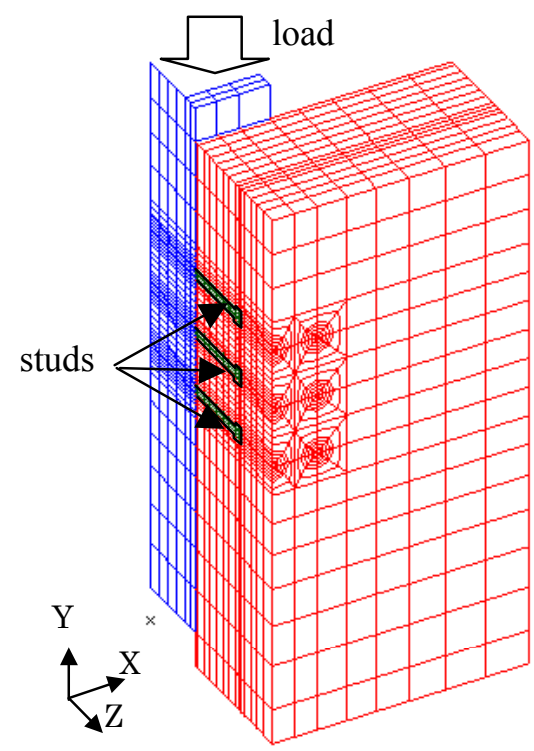

Fig.4 FE-model

Table 2 Material properties

\begin{tabular}{|c|c|c|c|c|}
\hline \multicolumn{2}{|c|}{ Model name } & $\begin{array}{c}\text { SP3-1 } \\
\text { SP4-1 }\end{array}$ & $\begin{array}{c}\text { SP3-2 } \\
\text { SP4-2 }\end{array}$ & $\begin{array}{c}\text { SP3-3 } \\
\text { SP4-3 }\end{array}$ \\
\hline \hline \multirow{2}{*}{$\begin{array}{c}\text { Concrete } \\
\mathrm{N} / \mathrm{mm}^{2}\end{array}$} & $f_{c}$ & 49.5 & 44.3 & 49.4 \\
\cline { 2 - 5 } & $f_{t}$ & 4.1 & 3.8 & 4.1 \\
\cline { 2 - 5 } & $E_{c m}$ & 37900 & 34400 & 37900 \\
\hline \hline \multirow{2}{*}{$\begin{array}{c}\text { Stud } \\
\mathrm{N} / \mathrm{mm}^{2}\end{array}$} & $f_{y s t}$ & \multicolumn{3}{|c|}{445} \\
\cline { 2 - 5 } & $f_{\text {ust }}$ & \multicolumn{3}{|c|}{530} \\
\cline { 2 - 5 } & $E_{s t}$ & \multicolumn{3}{|c|}{200000} \\
\hline \hline \multirow{2}{*}{$\begin{array}{c}\text { Reinforcement } \\
\mathrm{N} / \mathrm{mm}^{2}\end{array}$} & $f_{y s}$ & \multicolumn{3}{|c|}{600} \\
\cline { 2 - 4 } & $f_{u s}$ & \multicolumn{3}{|c}{200000} \\
\hline & $E_{s}$ & \multicolumn{3}{|c}{200000} \\
\hline \multirow{2}{*}{$\begin{array}{c}\text { Steel beam } \\
\mathrm{N} / \mathrm{mm}^{2}\end{array}$} & $E_{g}$ & \multicolumn{3}{|c}{} \\
\hline
\end{tabular}

cylinder tests, are shown in Table 2. The constitutive law for concrete is shown in Fig. 5. As for the compression region of concrete, the stress-strain curve is modeled in Eq. (1) - (3) of Eurocode $2^{17)}$. However, ultimate strain $\varepsilon_{c u}$ and post peak behavior are not considered here. The tension region is defined with a linear elastic model until the tensile strength $f_{t}$, and with a linear tension-softening model until the ultimate strain $\varepsilon_{t u}$. The ultimate strain $\varepsilon_{t u}$ is supposed to be the yield strength of reinforcement $\left(f_{y s} / E_{s}\right)$, because the slab consists of reinforced concrete.

$$
\frac{\sigma_{c}}{f_{c}}=\frac{k\left(\frac{\varepsilon_{c}}{\varepsilon_{c 1}}\right)-\left(\frac{\varepsilon_{c}}{\varepsilon_{c 1}}\right)^{2}}{1+(k-2)\left(\frac{\varepsilon_{c}}{\varepsilon_{c 1}}\right)}
$$




$$
\begin{aligned}
& \varepsilon_{c 1}=-0.0022 \\
& k=\left(1.1 E_{c m}\right) \cdot\left(\frac{\varepsilon_{c 1}}{f_{c}}\right)
\end{aligned}
$$

where $\varepsilon_{c}$ : strain of concrete, $\sigma_{c}$ : stress of concrete $\left(\mathrm{N} / \mathrm{mm}^{2}\right), f_{c}$ : compressive strength of concrete $\left(\mathrm{N} / \mathrm{mm}^{2}\right), \varepsilon_{c 1}$ : strain at the peak stress, $E_{c m}$ : Young's modulus of concrete $\left(\mathrm{N} / \mathrm{mm}^{2}\right)$.

The smeared crack model is applied to the general cracking behavior of concrete, and the discrete crack model is applied between the studs and the concrete surfaces. The cracks arise when the stress reaches the tensile strength $f_{t}$, and the full shear retention is supposed after cracking.

\section{b) Stud}

As shown in Fig. 6, the constitutive law for the studs is modeled by a multi-linear model based on the standard tensile tests ${ }^{18)}$. Yield strength $f_{y s t}$, ultimate strength $f_{u s t}$, Yong's modulus $E_{s t}$ are shown in

\section{Table 2.}

\section{c) Reinforcement}

The reinforcement is modeled by a bi-linear model based on the mill sheet. Yield strength $f_{y s}$, ultimate strength $f_{u s}$, Yong's modulus $E_{s}$ are shown in Table 2.

\section{d) Steel beam}

The steel beam is thick and rigid. It is modeled by a linear elastic model after confirming the validity in the preliminary analysis.

\section{(3) Failure criteria}

With respect to the failure criterion of concrete, the Drucker-Prager criterion is used as in shown in Eq. (4).

$$
\begin{aligned}
f(\sigma, \kappa) & =\sqrt{\frac{1}{2}\left[\left(\sigma_{1}-\sigma_{2}\right)^{2}+\left(\sigma_{2}-\sigma_{3}\right)^{2}+\left(\sigma_{3}-\sigma_{1}\right)^{2}\right]} \\
& +\frac{2 \sin \phi}{3-\sin \phi}\left(\sigma_{1}+\sigma_{2}+\sigma_{3}\right)-\frac{6 \cos \phi}{3-\cos \phi} c(\kappa)
\end{aligned}
$$

where $\sigma_{1}, \sigma_{2}, \sigma_{3}$ : principal stresses $\left(\mathrm{N} / \mathrm{mm}^{2}\right), \phi$ : internal friction angle in the Drucker-Prager criterion (deg.), $c(k)$ : equivalent cohesion $\left(\mathrm{N} / \mathrm{mm}^{2}\right)$.

It has been shown that the Drucker-Prager criterion overestimates strength ${ }^{19)}$ if it is applied to the high compressive concrete behavior in front of the lower portion of the stud in the push-out tests. Therefore 10 deg. is used for the internal friction angle ${ }^{20)}$ after confirming the validity in the preliminary analysis. The equivalent cohesion $c(k)$ is determined from the Eq. (5) with the theoretical solution of the internal friction angle ${ }^{21)}\left(\phi_{0}=58 \mathrm{deg}\right.$.). A general associated flow rule is used to calculate the plastic strain in-

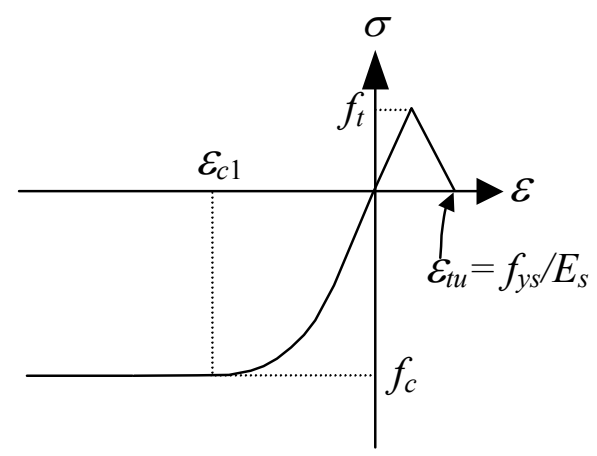

Fig.5 Constitutive law for concrete

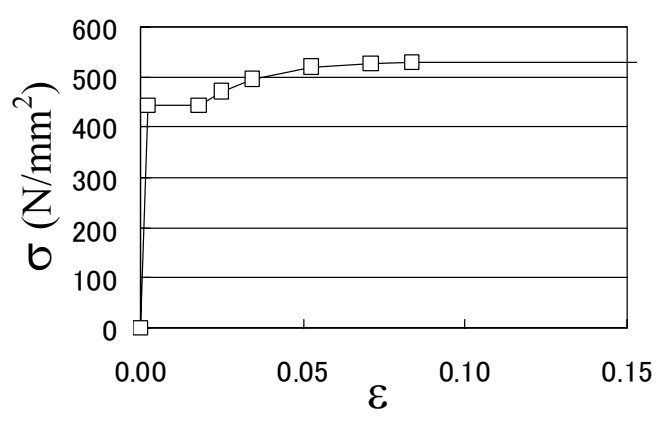

Fig.6 Constitutive law for studs

crement.

$$
c(\kappa)=\frac{1-\sin \phi_{0}}{2 \cos \phi_{0}} f_{c}
$$

where $c(k)$ : equivalent cohesion $\left(\mathrm{N} / \mathrm{mm}^{2}\right), \phi_{0}$ : theoretical internal friction angle to calculate the equivalent cohesion (deg.).

With respect to the yield criterion of studs and reinforcement the von Mises criterion was used as shown in Eq. (6).

$f(\sigma, \kappa)=\sqrt{\frac{1}{2}\left[\left(\sigma_{1}-\sigma_{2}\right)^{2}+\left(\sigma_{2}-\sigma_{3}\right)^{2}+\left(\sigma_{3}-\sigma_{1}\right)^{2}\right]}-\sigma(\kappa)$

where $\sigma_{1}, \sigma_{2}, \sigma_{3}$ : principal stresses $\left(\mathrm{N} / \mathrm{mm}^{2}\right), \sigma(k)$ : uniaxial yield stress $\left(\mathrm{N} / \mathrm{mm}^{2}\right)$.

\section{(4) Analytical results}

a) Influence of chemical bond and friction between the steel beam and the concrete surface

Fig. 7 shows the comparisons of the load-slip curves between the test results and the analytical results. 'FEM; basic' considers the material nonlinearity of the studs, of the concrete, and of the reinforcement but does not consider the chemical bond and friction between the steel beam and the concrete surface.

It is recognized from Fig. 7 that the load-slip curves of 'FEM;basic' are at about $13 \%$ lower than 

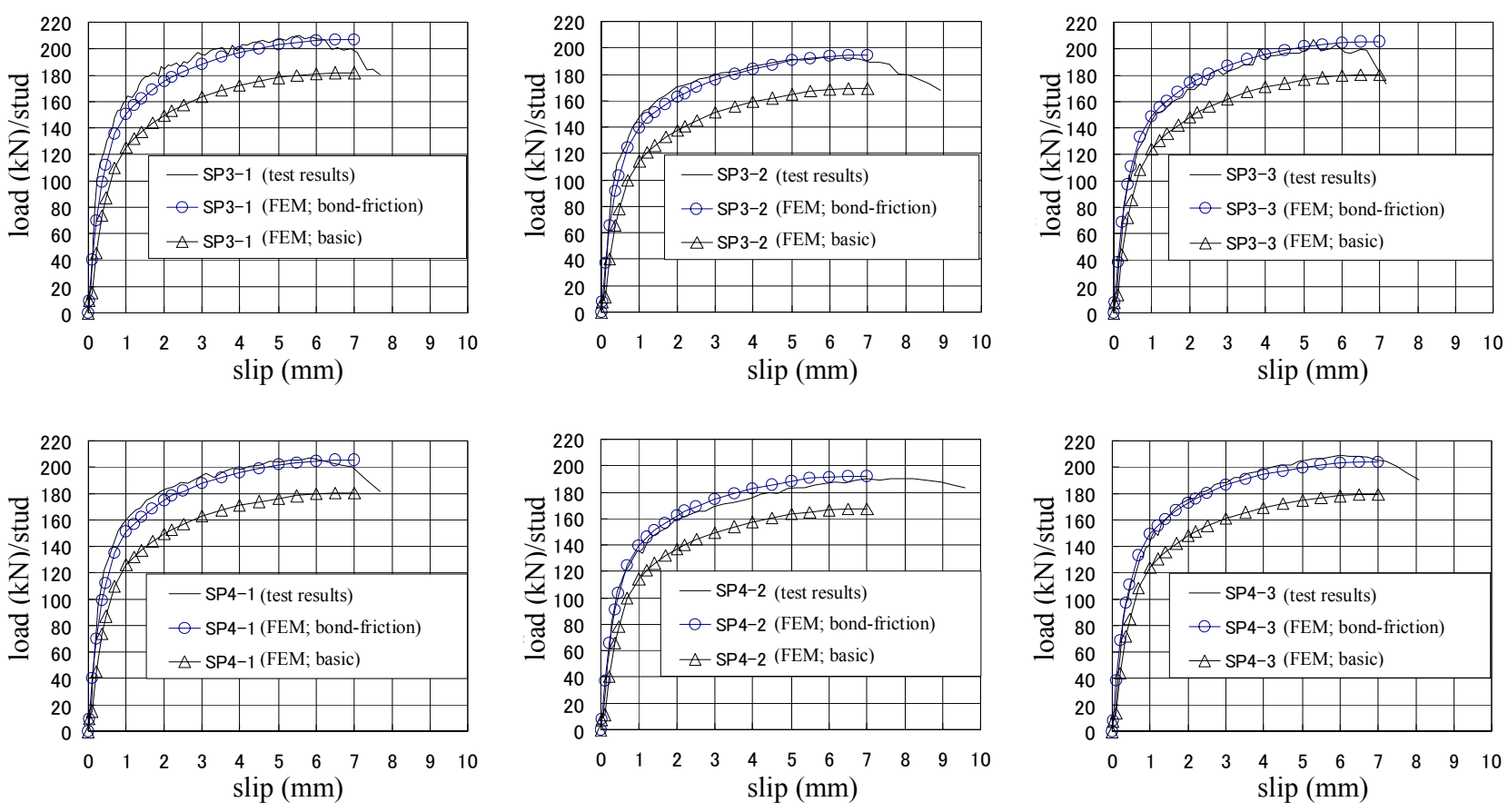

Fig.7 Comparisons of the load-slip curves between the test results and the analytical results

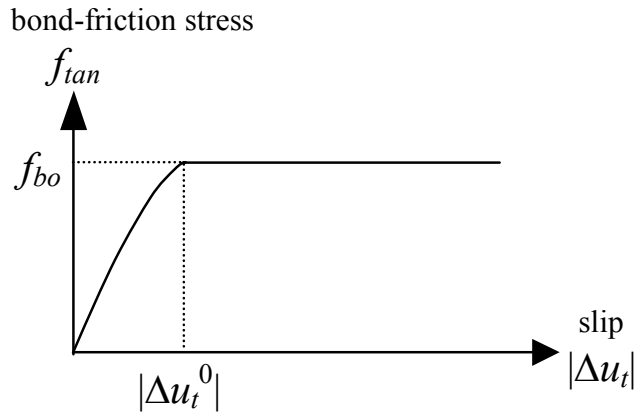

Fig.8 Bond-friction model

those of the test results. This is mainly because there is an influence of chemical bond and friction between the steel beam and the concrete surface to be taken account of.

Accordingly, the bond-friction model as shown in Fig. 8 and Eq. (7) - (8), which is developed from Dörr's bond-slip model ${ }^{22)}$, are incorporated into the analytical model allowing for the following things: $0 \leq \Delta u_{t}<\Delta u_{t}^{0}$ :

$$
f_{\text {tan }}=\frac{f_{b o}}{1.9}\left(5\left(\frac{\Delta u_{t}}{\Delta u_{t}^{0}}\right)-4.5\left(\frac{\Delta u_{t}}{\Delta u_{t}^{0}}\right)^{2}+1.4\left(\frac{\Delta u_{t}}{\Delta u_{t}^{0}}\right)^{3}\right)
$$

$\Delta u_{t} \geq \Delta u_{t}^{0}$ :

$$
f_{\text {tan }}=f_{\text {bo }}
$$

1) The influence of chemical bond and friction between the steel beam and the concrete surface, which should be the difference between the
'FEM; basic' and the test results, is similar to the bond-friction behavior between reinforcement and concrete.

2) Adaptability to the user-supplied subroutines in the analytical program.

As shown in Fig. 8 and Eq. (7) - (8), constant friction stress is supposed after the breaking of the chemical bond. The reason is as follows:

In the push-out tests, the loading direction and the direction of the surface pressure between the steel beam and the concrete surface are perpendicular to each other. Therefore, it can be supposed that the surface pressure is not sensitive to the loading and it is also supposed that the friction stress, which depends on the surface pressure, is relatively constant even if the load changes. Whether the hypothesis is true or false is not evident here, the validity will be assessed later.

According to the previous investigations ${ }^{23)}$, the maximum bond stress $f_{b o}$ is about $0.5 \mathrm{~N} / \mathrm{mm}^{2}$. However, it is indicated that if the stress concentration at the edge is small, the maximum bond stress may large. In the bond-friction model here, $0.9 \mathrm{~N} / \mathrm{mm}^{2}$ is used for $f_{b o}$ after comparing some of the analytical results with the test results.

Concerning the slip at the peak chemical bond $\left|\Delta u_{t}{ }^{0}\right|, 0.06 \mathrm{~mm}$, which is the standard value of the Dörr's bond-slip model ${ }^{22)}$, is set in consideration of the test results ${ }^{23)}$ which vary between 0.02 and 0.05 $\mathrm{mm}$. In the analysis, however, no obvious difference is seen in the load-slip curves if $\left|\Delta u_{t}^{0}\right|$ varies between 0.02 and $0.06 \mathrm{~mm}$. 


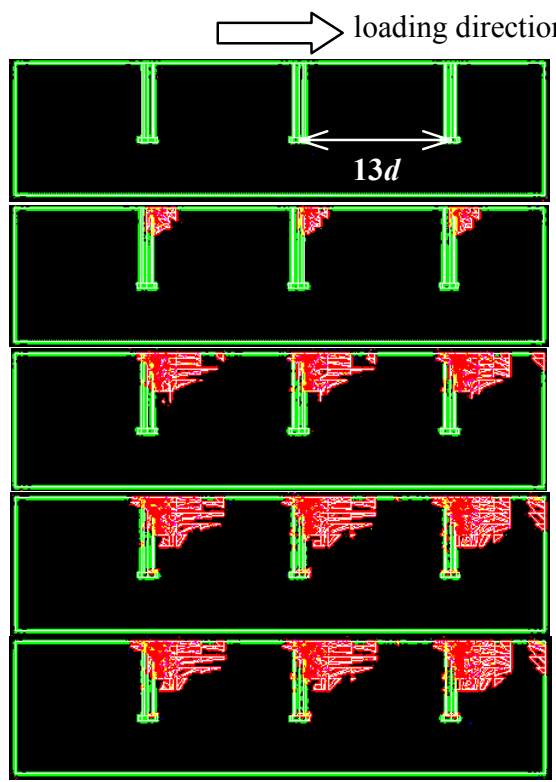

(a) $13 \mathrm{~d}$ model

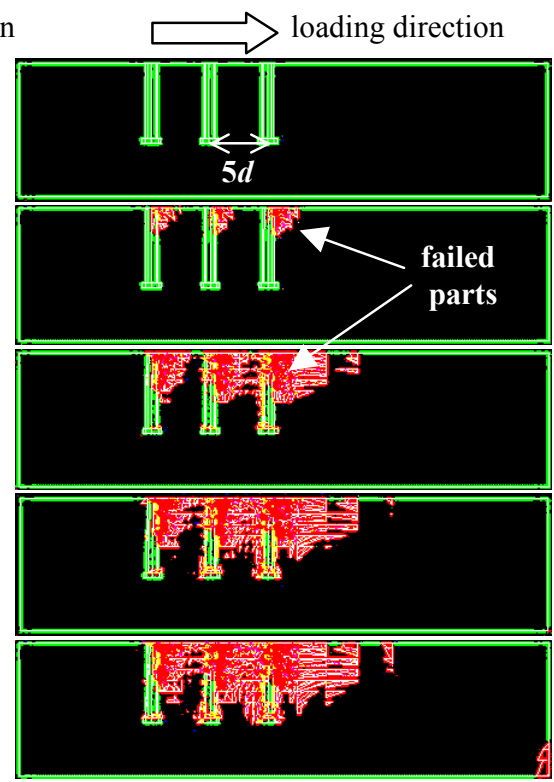

(b) SP3-2 5d model

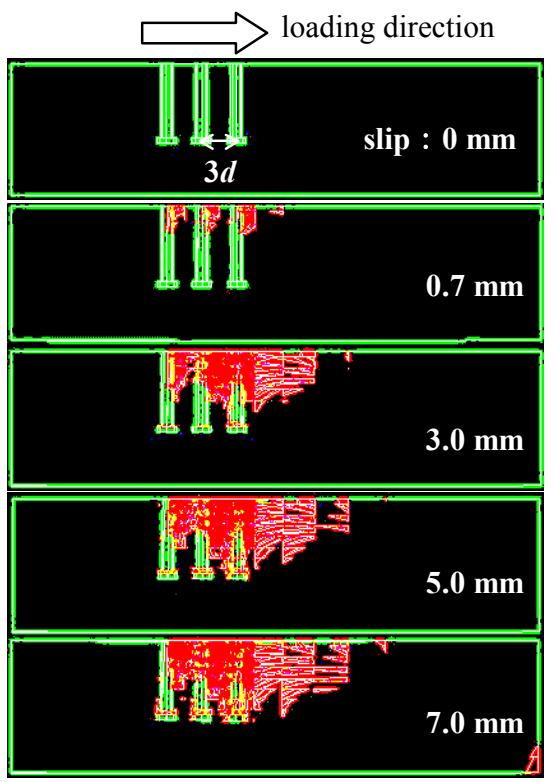

(c) $3 \mathrm{~d}$ model

Fig.9 Failure mode of concrete at the cutting surface

Further studies will be needed for the bond-friction model; whether, for example if it is defined as a function of the surface pressure between the steel beam and the concrete surface, or if it is defined as a function of the tensile strength of concrete.

In addition, concerning the casting direction of concrete in the specimens, it is recognized that bleeding occurs on the surface of the studs when the specimens are placed in the vertical position, or bleeding occurs on the surface between the steel beam and the concrete slab when the specimens are placed in the upside-down position ${ }^{24)}$. Therefore, further studies will be needed for the bond-friction model, comparing with the test results.

Fig. 7 shows that 'FEM;bond-friction' which considers the bond-friction model is in good agreement with the test results. It should be noted that the load-slip curves of the test results drop due to the shear failure of the studs. In the analysis, however, post peak behavior of the concrete and the studs is not considered, so a drop in the load-slip curves cannot be a part of the analysis.

Therefore, in the analysis, an analytical maximum slip (an analytical longitudinal slip at the maximum shear strength) is set at $7 \mathrm{~mm}$, which is decided according to the fact that analytical load becomes almost constant at the slip. Even though there is some variation in the test results, the analytical maximum slips indicate good agreement with the test results.

It is concluded that practicability of the proposed analytical method to simulate the load-slip curves of the push-out behavior is verified on the basis of the comparison with the test results. It is also noted that the hypothesis of the constant friction stress after breaking the chemical bond is proved to be reasonable.

\section{b) Failure mode}

In addition to the 'SP3-2 $5 \mathrm{~d}$ model' (the longitudinal spacing of studs $\left.d_{l}=5 d\right)$, the '13d model' $\left(d_{l}=\right.$ $13 d$; maximum spacing) and the ' $3 \mathrm{~d}$ model' $\left(d_{l}=3 d\right.$; minimum spacing) were prepared to investigate the failure mechanism.

Fig. 9 shows the failure mode of concrete at the cutting surface of the concrete slab. The elements which are beyond the Drucker-Prager criterion are highlighted as failed parts.

The ' $13 \mathrm{~d}$ model' shows that failure happened to the compressive stress zone in front of the bottom portion of the studs at a slip of $0.7 \mathrm{~mm}$. Following this, the failed parts enlarged in a triangle shape (in the cone shape, 3-dimensionally). However, the failed parts are still independent of each other at a slip of 7 $\mathrm{mm}$. Accordingly, it is indicated that the ' $13 \mathrm{~d}$ model' behaves similar to the standard arrangement of studs where the studs are arranged in fully large spacing and it is also indicated that the influence of the grouped arrangement is small.

On the other hand, the 'SP3-2 5d model' shows a behavior similar to the ' $13 \mathrm{~d}$ model' at a slip of $0.7 \mathrm{~mm}$ but the failed parts in the compressive stress zone reach the next shank of the stud and the failed parts near the head of the stud are also seen at a slip of 5 $\mathrm{mm}$. The overlap of the failed parts can be seen at a slip of $7 \mathrm{~mm}$. The overlap of the failed parts is also recognized in the test results and this mode is unique to the grouped arrangement. As to the length of the failed parts in the longitudinal direction, test results are $3 d-5 d$, and the analytical results are $4 d-5 d$. So 


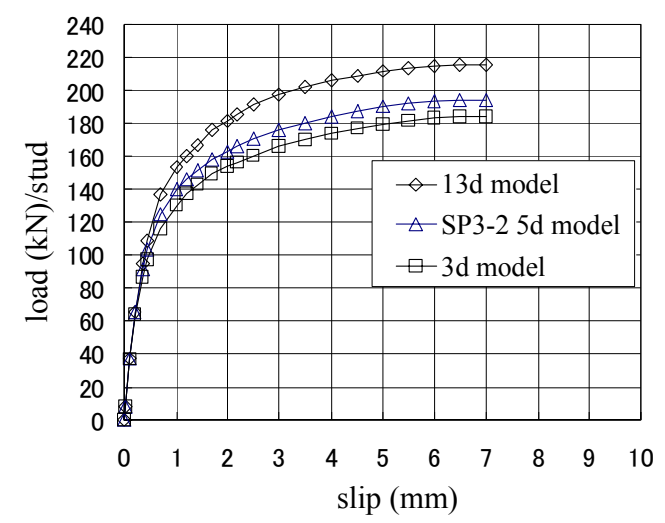

Fig.10 Load-slip curves

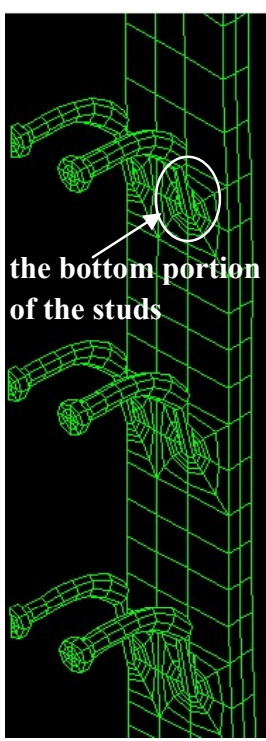

(a) $13 \mathrm{~d}$ model

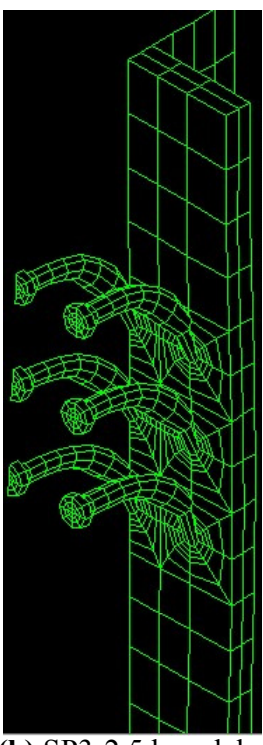

(b) SP3-2 5d model

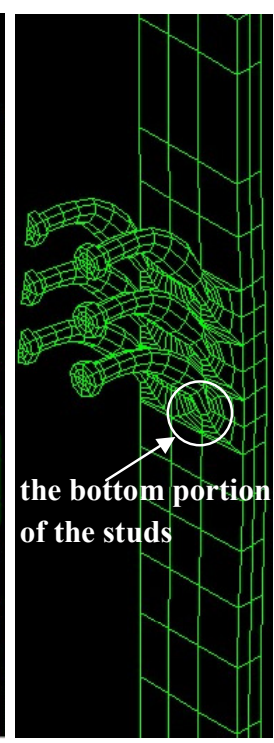

(c) $3 \mathrm{~d}$ model
Fig.11 Shape of the studs (x 18)

the analytical results are relatively larger than those of the test results.

The '3d model', which has the minimum longitudinal spacing, shows that overlap of the failed parts is already seen at a slip of $3 \mathrm{~mm}$ and a concentrated failure mode is recognized in the grouped arrangement at a slip of $7 \mathrm{~mm}$.

Fig. 10 showing the load-slip curves indicates that ' the SP3-2 5d model' is about $9.9 \%$ lower and ' $3 \mathrm{~d}$ model' is about $14.7 \%$ lower than the ' $13 \mathrm{~d}$ model'. Obviously, the reason is the difference in the degree of failure of concrete near the studs as shown in Fig. 9. As the degree of failure of concrete becomes large, it is supposed that binding force to the studs becomes small and the shear strength of studs therefore becomes small.

It is supposed that the reason why the difference of the dropping rate of the grouped arrangement to the standard arrangement is 5\% in the test results (in Table 1), and $9.9 \%$ in the analytical results is some difference in the hypotheses in the analytical model and the some variation in the test results. Compari- sons of the shear reduction between the existing test results and analytical results will be discussed in 4.(3) c).

The shape of the studs (magnified at 18 times) is shown in Fig. 11. The '13d model' shows that shear failure mode of the studs occurs because the shear deformation of the bottom portion of the studs is significant. On the other hand, the ' $3 \mathrm{~d}$ model' shows that bending-shear failure mode of studs occurs because the deformation of the bottom portion of the studs is small and the bending-shear deformation of the lower portion of the studs is relatively large compared with the ' $13 \mathrm{~d}$ model'. This is the reason why the degree of failure of concrete near the lower portion of studs becomes large and binding force to the studs becomes small.

It is concluded that bending-shear failure mechanism of the grouped arrangement of studs is as follows:

(1) Failure happens to the compressive stress zone in front of the bottom portion of the studs.

(2) As the slip becomes larger, the failure in the compressive stress zone of concrete reaches the next shank of the stud and the overlap of the failed parts is seen.

(3) As the degree of failure of concrete becomes large, the binding force to the studs becomes small and the bending deformation of the lower portion of studs becomes significant.

(4) The bending-shear failure mode of studs along with the failure of concrete occurs and reaches the ultimate state.

It is indicated that the strength of the bending-shear failure mode of studs in the grouped arrangement is smaller than the strength of the shear failure mode of studs in the standard arrangement due to the failure mechanism above.

\section{INVESTIGATION OF THE SHEAR STRENGTH OF THE GROUPED AR- RANGEMENT}

Parametric analyses were conducted in order to investigate the shear strength of the grouped arrangement of studs systematically.

Prospective dominant parameters of the shear strength of the grouped arrangement of studs are the concrete strength, the longitudinal spacing of studs, the transverse spacing of studs, the size of the concrete slab, the content of reinforcement, the size of studs, the material strength of studs, the material strength of reinforcement, and the size of the steel beam, etc. 
Table 3 Outline of the analytical models

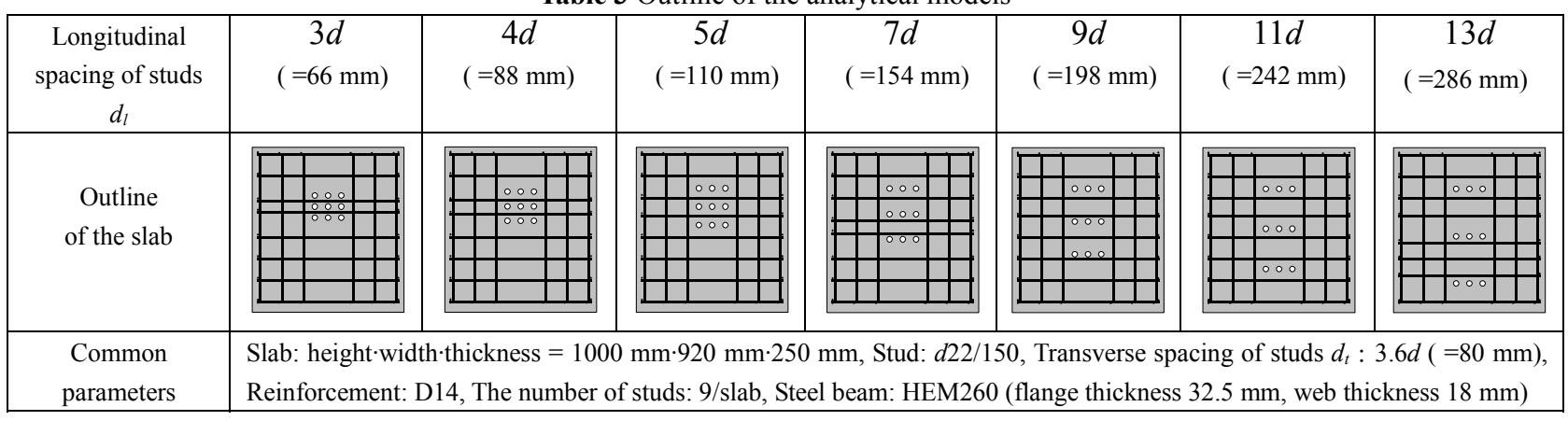

Table 4 Concrete classes

\begin{tabular}{|c|c|c|c|c|}
\hline Concrete class & $\mathrm{C} 25 / 30$ & C30/37 & $\mathrm{C} 40 / 50$ & C50/60 \\
\hline$f_{c} \quad\left(\mathrm{~N} / \mathrm{mm}^{2}\right)$ & 25 & 30 & 40 & 50 \\
\hline$f_{t} \quad\left(\mathrm{~N} / \mathrm{mm}^{2}\right)$ & 2.6 & 2.9 & 3.5 & 4.1 \\
\hline$E_{c m}\left(\mathrm{~N} / \mathrm{mm}^{2}\right)$ & 30500 & 32000 & 35000 & 37000 \\
\hline
\end{tabular}

In this chapter, parametric analyses on concrete strength and on the longitudinal spacing of studs, which should be the dominant parameters according to the outcomes of the previous chapter, are performed under conditions where the transverse spacing of studs, the size of the concrete slab, the content of reinforcement, the size of studs, the material strength of studs, the material strength of reinforcement, the size of the steel beam are kept constant and also the sufficient size of the concrete slab, the sufficient size of the steel beam, and the sufficient content of reinforcement are satisfied.

\section{(1) Analytical models}

The base of the analytical models is SP3, and longitudinal spacing of studs $d_{l}$ is changed to $3 d, 4 d, 5 d$, $7 d, 9 d, 11 d, 13 d$, respectively. The outline of the models is shown in Table 3. Arrangement of the reinforcement is slightly changed to avoid the overlapping with studs.

\section{(2) Material models and material properties}

Representative concrete classes in Eurocode 2 are adopted as shown in Table 4. Putting these values in the Eq. (1) - (3) of 3.(2) a), the constitutive law for concrete is obtained.

As to the studs, the reinforcement, and the steel beam, the same models and the same material properties in 3.(2) are used. As to the influence of chemical bond and friction between the steel beam and the concrete slab, the bond-friction model in 3.(4) a) is used with the same maximum bond stress $f_{b o}=0.9 \mathrm{~N} / \mathrm{mm}^{2}$.

\section{(3) Analytical results}

\section{a) Influence of the concrete strength}

Fig. 12 shows the comparisons of the load-slip curves varying the concrete strength and keeping the longitudinal spacing of studs constant. Fig. 13 shows the relationship between the shear strength and the concrete strength. It is recognized from these figures that as the concrete strength becomes small, the shear strength also becomes small. The same size and the same material properties of studs are used here but the difference in the load-slip behavior is seen. The reason is the difference in the degree of failure of concrete around the studs.

Fig. 14 shows the shape of the studs at a slip of 7 $\mathrm{mm}$. The '5d_C25/30 model', which is the lowest concrete strength model, shows that studs slightly incline from the top and bending-shear deformation of the lower portion of the studs is significant. Because the shear deformation of the bottom portion of the studs is small, it is supposed that the degree of failure of concrete around the studs became large before the potential performance of studs was utilized. It is supposed that the shear strength therefore became small.

On the other hand, the ' $5 \mathrm{~d}$ C $50 / 60$ model', which is the highest concrete strength model, shows that studs are straight from the top to the middle, but bending deformation is seen at the lower portion and the shear deformation is significant at the bottom portion. The reason is that because of the higher concrete strength, failure of the concrete around the studs is less likely to occur compared with the smaller concrete strength. Because the binding force to the studs is large, it is supposed that the shear failure mode of the studs occurred and the shear strength therefore became large. Not detailed here, the '5d_C $30 / 37$ model', and the '5d_C40/50 model' show the intermediate failure mode between the ' $5 \mathrm{~d} \_\mathrm{C} 25 / 30$ model' $^{\prime}$ and the '5d_C50/60 model'.

\section{b) Influence of the longitudinal spacing of studs}

Fig. 15 shows the comparisons of the load-slip curves varying the longitudinal spacing of studs $d_{l}$ and keeping the concrete strength constant. Fig. 16 shows the relationship between the shear strength and the longitudinal spacing factor $C_{l}\left(=d_{l} / d\right)$. The reason why the difference in the shear strength is seen is the difference in the degree of failure of concrete around the studs because of the interaction 

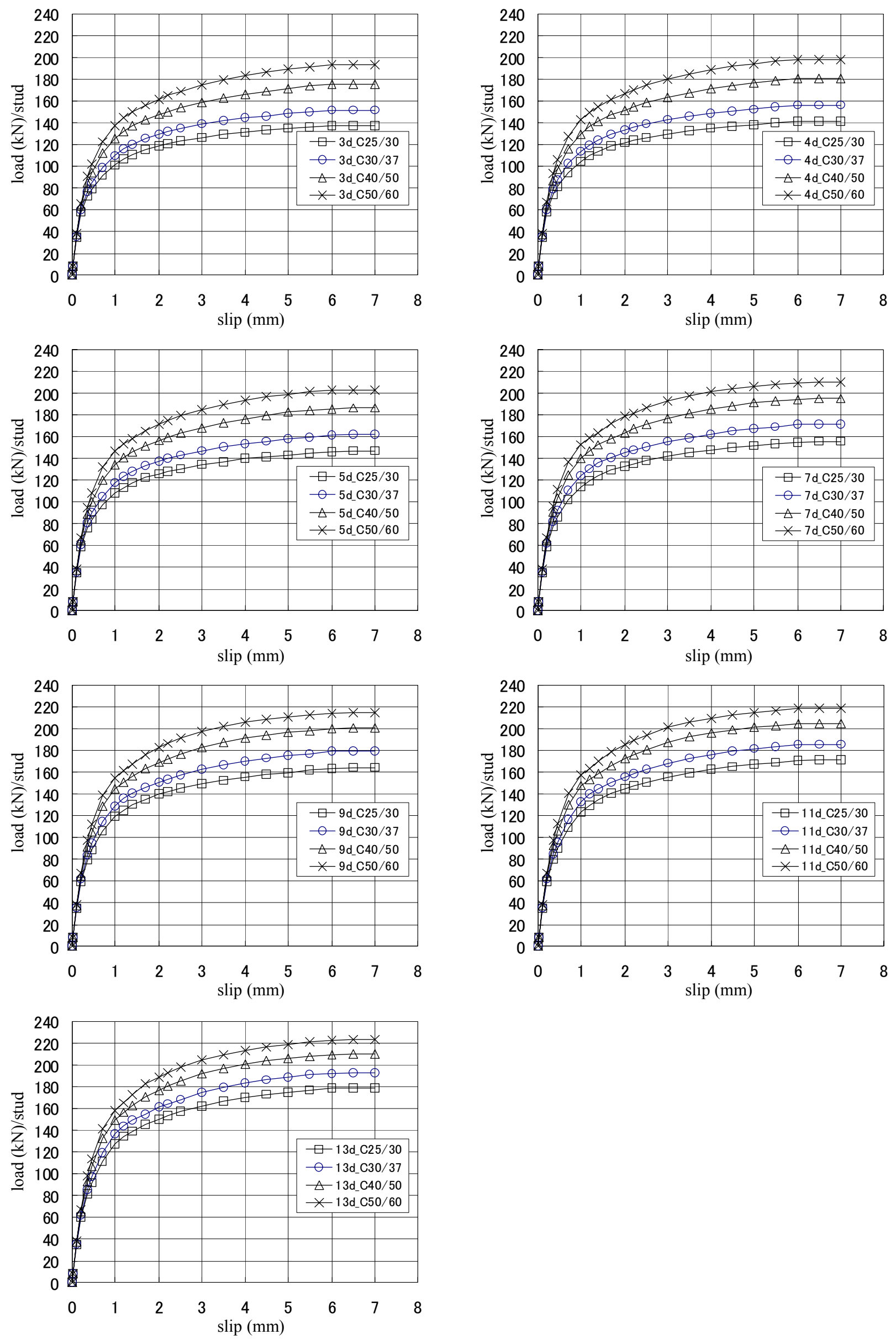

Fig.12 Load-slip curves (Influence of the concrete strength) 


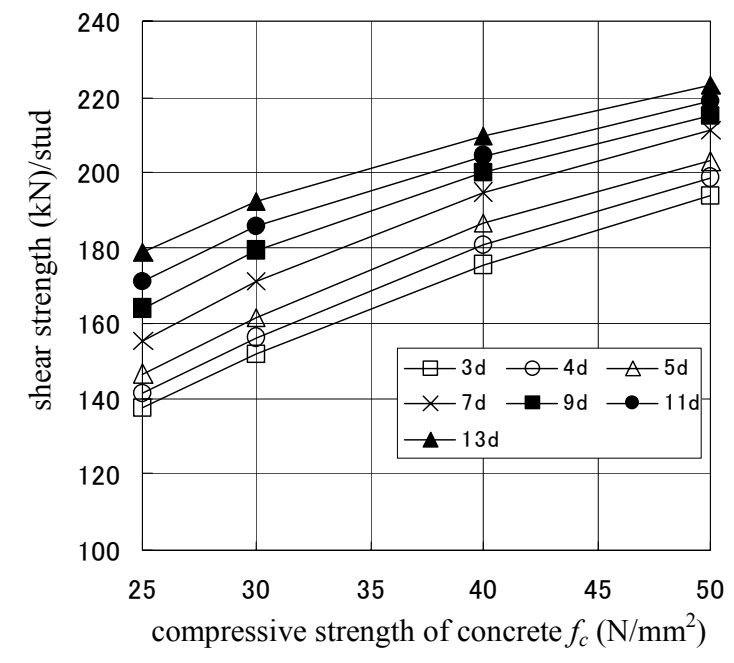

Fig.13 Relationship between the shear strength and the concrete strength
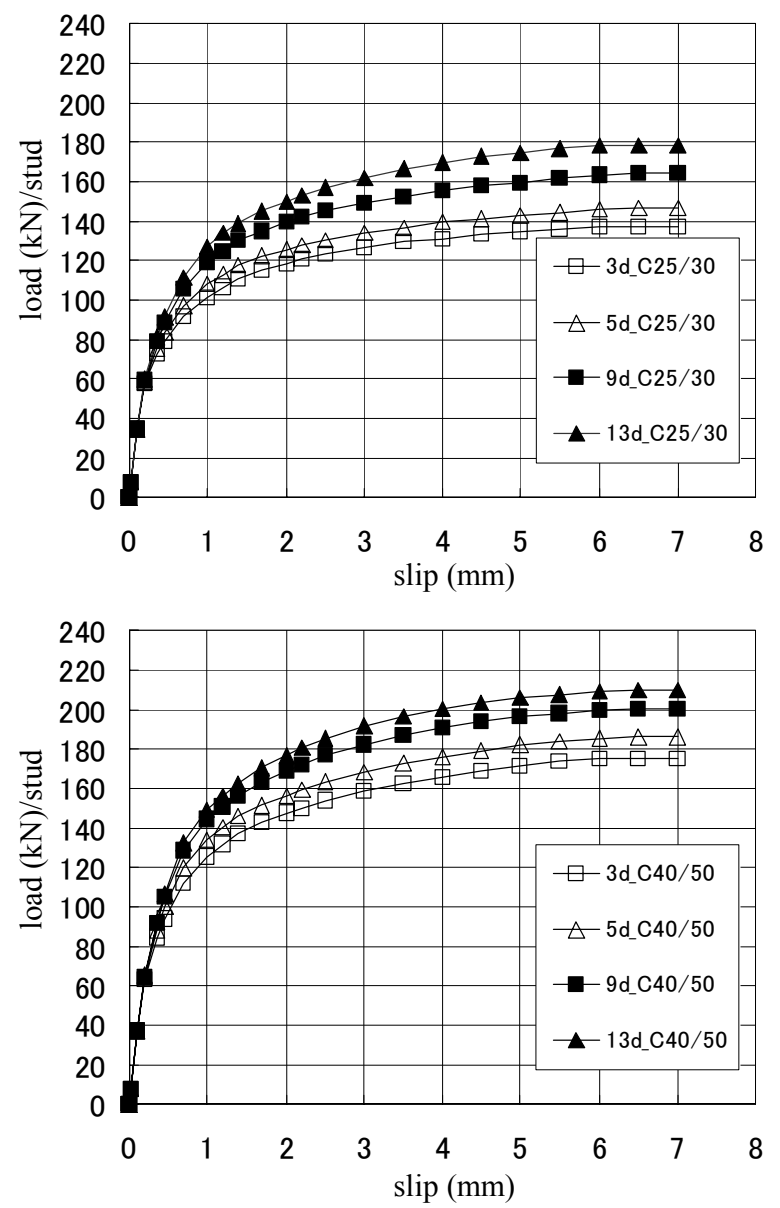

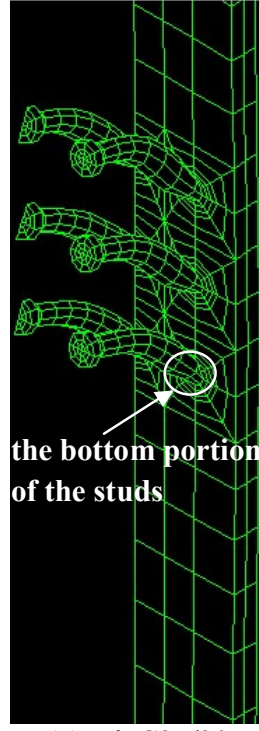

(a) $5 \mathrm{~d}+\mathrm{C} 25 / 30$

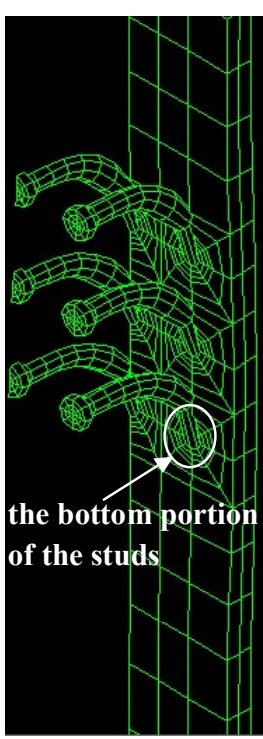

(b) $5 \mathrm{~d} \_\mathrm{C} 50 / 60$
Fig.14 Shape of the studs (x 18)
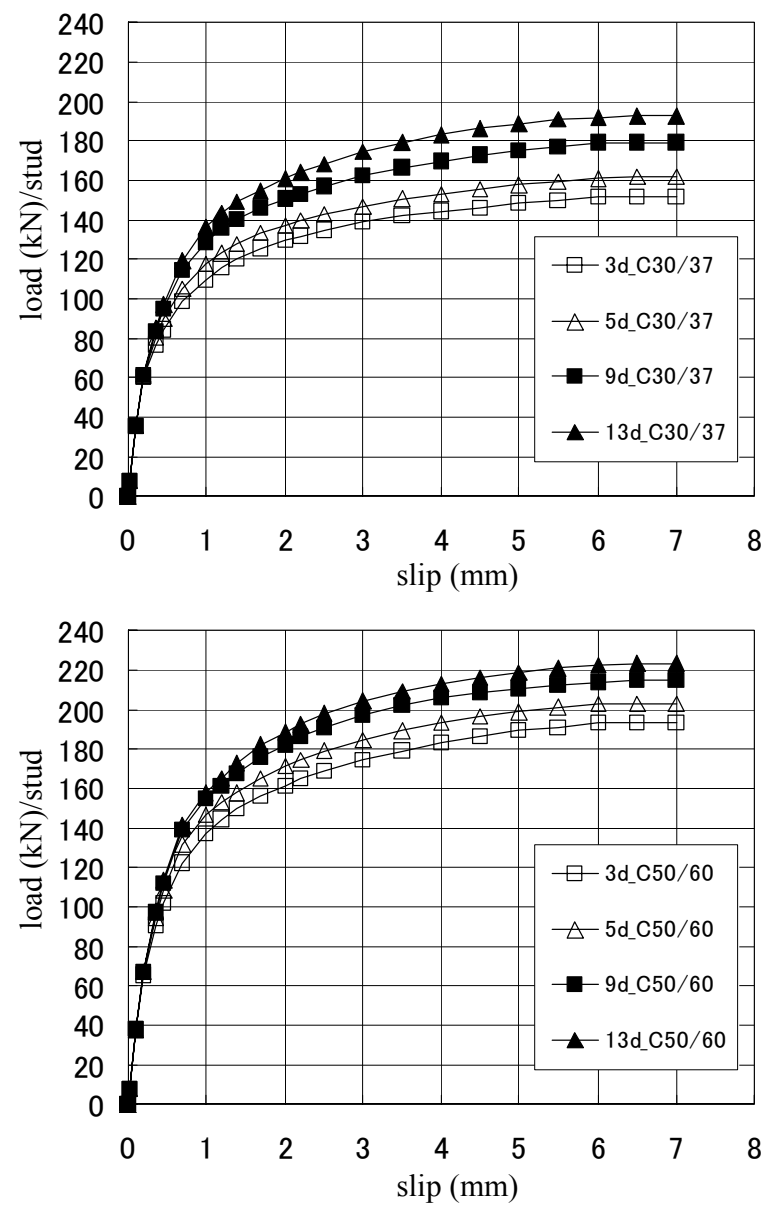

Fig.15 Load-slip curves (Influence of the longitudinal spacing of studs)

with the next studs as described in 3.(4) b). As $C_{l}$ becomes small, it is supposed that the influence of the next studs, namely, the influence of the grouped arrangement of studs becomes large and the shear strength therefore becomes small.

\section{c) Shear strength reduction factor of the grouped arrangement}

The relationship between the shear strength reduction factor $\eta$ to the ' $13 \mathrm{~d}$ model' in each concrete strength and the longitudinal spacing factor $C_{l}\left(=d_{l} /\right.$ 


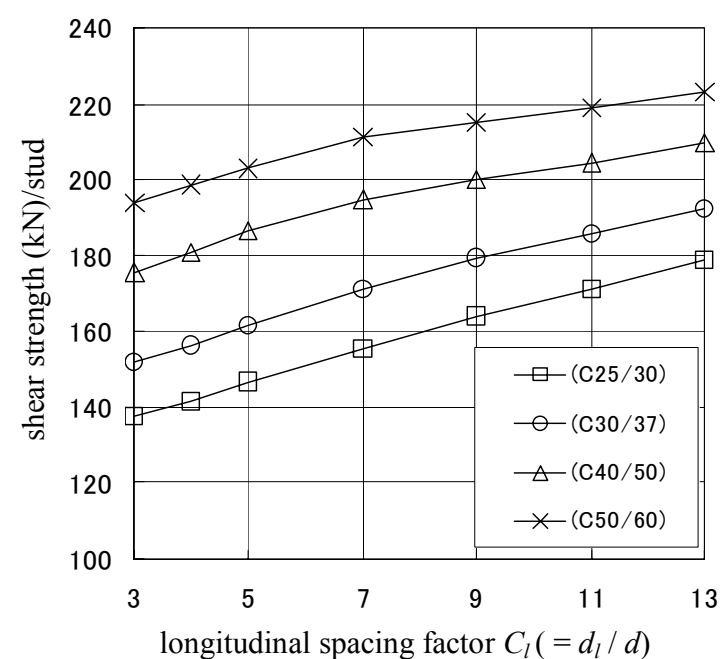

Fig.16 Relationship between the shear strength and the longitudinal spacing factor $C_{l}\left(=d_{l} / d\right)$

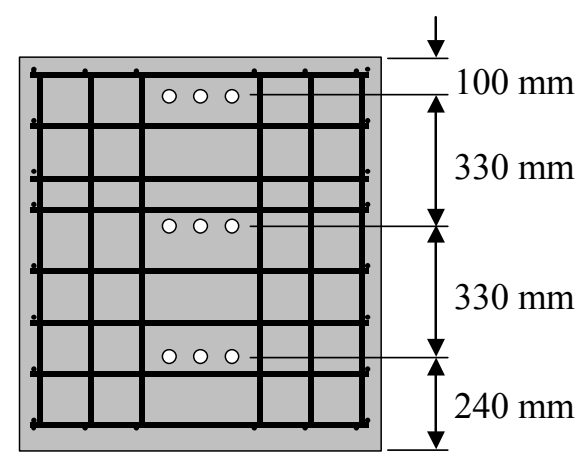

Fig.18 Outline of the concrete slab of the $15 \mathrm{~d}$ model

d) compared with the existing test results ${ }^{14), 25)-27)}$ is shown in Fig. 17.

The ' $15 \mathrm{~d}$ model' is added because the strength of the ' $13 \mathrm{~d}$ model' still tends to go up. The outline of the concrete slab of the '15d model' is illustrated in Fig. 18. As shown in Table 3 and Fig. 18 that the distances between the top of the slab and center of the upper studs are 294 - $250 \mathrm{~mm}$ for the ' $3 \mathrm{~d}$ model' - '13d model', but, $100 \mathrm{~mm}$ for the ' $15 \mathrm{~d}$ model' to secure the large longitudinal spacing of the studs $\left(d_{l}=330 \mathrm{~mm}\right)$. The other parameters are same.

Concerning the test results, the shear strength reduction factor $\eta$ to the case of the largest $C_{l}$ is plotted with the compressive strength of concrete $f_{c}$ $\left(\mathrm{N} / \mathrm{mm}^{2}\right)$. However, if the largest $C_{l}$ is less than 13, Eq. (9) - (12), which will be described later, are used for the correction.

As shown in Fig. 17, as $C_{l}$ becomes large, the shear strength reduction factor of the analytical results becomes large and peaks at $C_{l}=13$. In addition, according to the investigation in 3.(4) b), it is indicated that the ' $13 \mathrm{~d}$ model' behaves in a similar way to

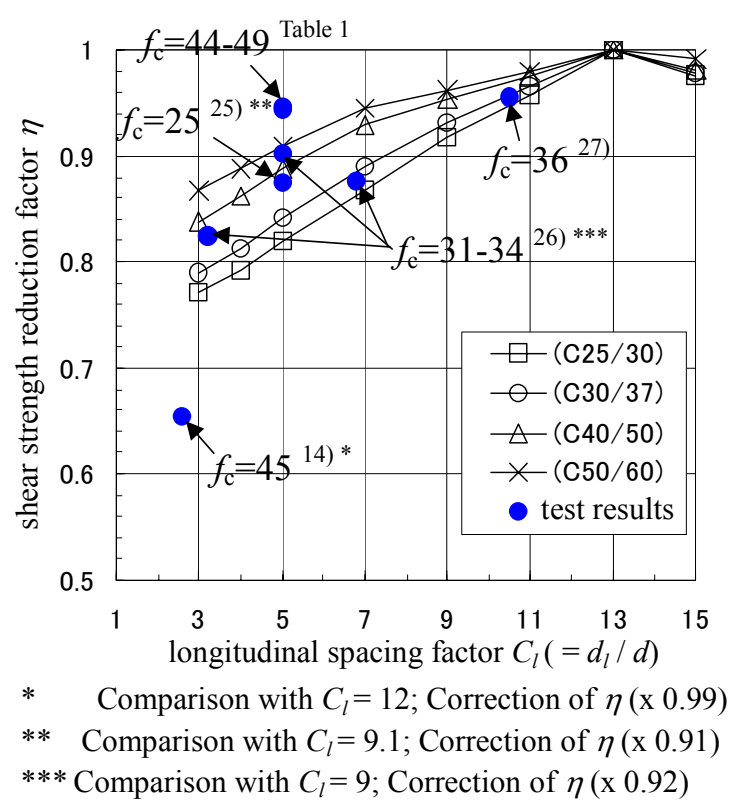

Fig.17 Relationship between the shear strength reduction factor $\eta$ and the longitudinal spacing factor $C_{l}\left(=d_{l} / d\right)$

the standard arrangement of the studs. Therefore, the influence of the grouped arrangement is small enough to be negligible if $C_{l}$ is greater than 13 .

One of the reasons why the slight reduction of the shear strength in the '15d model' occurs compared with the strength in the ' $13 \mathrm{~d}$ model' is the difference in the distance between the top of the slab and the center of the upper studs.

Even though there are not many data points from the test results and there is some variation in them, as $C_{l}$ becomes small, it is seen that the reduction factor $\eta$ becomes small as in the analytical results and if $C_{l}$ is $5-7$ with a lower compressive strength concrete, the reduction factor $\eta$ becomes less than 0.9. It should be noted that the reason why the $\eta$ of reference 14 is significantly smaller is that the much narrower spaced grouped arrangement is used in the tests (both longitudinal and transverse spacing of studs are $2.6 d$ ).

\section{(4) Proposition of the shear strength reduction equations of the grouped arrangement}

Based on the analytical results in Fig. 17, the shear strength reduction equations of the grouped arrangement are proposed in Fig. 19 and in Eq. (9) (13).

$3 \leq C_{l}<13$ :

$\mathrm{C} 25 / 30$;

$$
\eta=0.023 C_{l}+0.70
$$

$\mathrm{C} 30 / 37$;

$$
\eta=0.021 C_{l}+0.73
$$




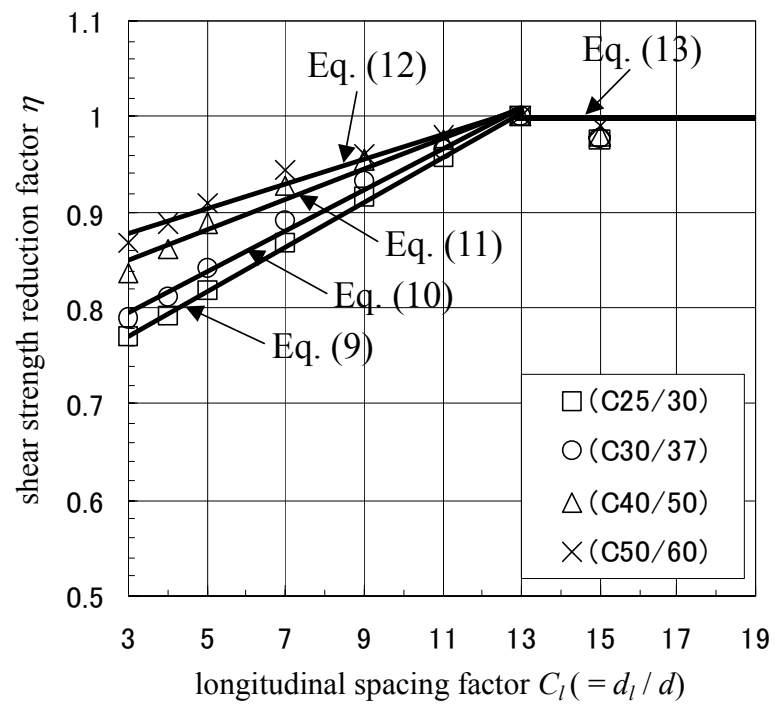

Fig.19 Shear strength reduction equations

$\mathrm{C} 40 / 50$;

$$
\eta=0.016 C_{l}+0.80
$$

C50/60;

$$
\eta=0.013 C_{l}+0.84
$$

$C_{l} \geq 13:$

$$
\mathrm{C} 25 / 30 \text { - C50/60; }
$$$$
\eta=1.0
$$

Based on the investigation in 4.(3), equations for each concrete strength are estimated for $3 \leq C_{l}<13$, using the linear least squares fitting. A constant value $\eta=1.0$ (without reduction) is used for $C_{l} \geq 13$.

At first, the reduction factor $\eta$ is calculated from the Eq. (9) - (13). Then, the shear strength of the grouped arrangement of studs is obtained by multiplying the reduction factor $\eta$ and the shear strength of the standard arrangement of studs.

Care should be taken that the sufficient size of the concrete slab, the steel beam, the studs, and the sufficient content of reinforcement as shown in Table 3, and the sufficient material strength of studs as shown in Table 2 should be satisfied for the application of the equations. If different parameters are used, the results may differ and another study will be needed.

\section{CONCLUSIONS}

A study was conducted in order to investigate the shear strength of the grouped arrangement of studs. The findings of the study are as follows:

(1) The shear strength behavior of studs is simulated by the proposed analytical method with sufficient accuracy using the material nonlinearity of the studs, the concrete, and the reinforcement, combining the smeared crack model, the discrete crack model, and the bond-friction model.

(2) It is concluded from the test results and analytical results that the bending-shear failure mechanism of the grouped arrangement of studs is as follows:

a) Failure happens to the compressive stress zone in front of the bottom portion of the studs.

b) As the slip becomes larger, the failure in the compressive stress zone of concrete reaches the next shank of the stud and an overlap of the failed parts is seen.

c) As the degree of failure of concrete becomes large, the binding force to the studs becomes small and the bending deformation of the lower portion of studs becomes significant.

d) The bending-shear failure mode of studs along with the failure of concrete occurs and reaches the ultimate state.

It is indicated that the strength of the bending-shear failure mode of studs in the grouped arrangement is smaller than the strength of the shear failure mode of studs in the standard arrangement due to the failure mechanism above.

(3) If the longitudinal spacing of studs is kept constant, as the concrete strength becomes small, the shear strength also becomes small. The reason is the difference in the degree of failure of concrete around the studs.

(4) If the concrete strength is kept constant, as $C_{l}$ becomes small, the shear strength also becomes small. The reason is the influence of the next studs, that is, the influence of the grouped arrangement of studs.

(5) As $C_{l}$ becomes large, the shear strength reduction factor $\eta$ of the analytical results becomes large and peaks at $C_{l}=13$. In addition, according to the investigation in 3.(4) b), it is indicated that the ' $13 \mathrm{~d}$ model' behaves in a similar way to the standard arrangement of studs. Therefore, it is indicated that the influence of the grouped arrangement is small enough to be negligible if $C_{l}$ is greater than 13.

(6) It is indicated that if $C_{l}$ is less than $5-7$ with the lower compressive strength concrete, the influence of the grouped arrangement becomes large.

(7) Based on the results of the parametric analyses, shear strength reduction equations for the grouped arrangement to the standard arrangement are proposed. 
ACKNOWLEDGMENT: The research was sponsored by the then NKK Corporation (now JFE), Japan and ICOM Steel Structures, EPFL, Switzerland. We would like to thank Professor Dr. M.A. Hirt, for his valuable suggestions. We would also like to thank Dr. A. Nussbaumer, for his constructive opinions. Assistance for the push-out tests by Messrs. Pidoux, Guex, Demierre, Reist, Lääne, and Imhof are gratefully appreciated. Last but not least, we would like to thank Associate Professor M. Tomida, Ishikawa National College of Technology for discussions about the test results.

\section{REFERENCES}

1) Yoda, T. : Steel-concrete composite bridges and connection technologies, Katayana Technical Report, Vol. 19, pp. 2-8, 2000. (in Japanese)

2) Japan Road Association: Design Specifications of Highway Bridges, Part II, 2002.3. (in Japanese)

3) European Committee for Standardization: Eurocode 4, Design of composite steel and concrete structures, 1994.

4) Lebet, J.-P. : Comportement des ponts mixtes acier - béton avec interaction partielle de la connexion et fissuration du béton, Thèse 661, EPFL, Lausanne, 1987.

5) Lebet, J.-P. : Ponts mixtes avec liaison acier - béton par groupes de goujons, IABSE Symposium, Brussels, pp. 233-238, 1990

6) Okubo, N., Kurita, A., Nakajima, S., Komatsu, K., and Hashimoto, K. : Experimental study on grouped stud shear connectors for composite girder bridges, J. Steel Constr. Eng., JSSC, Vol.8, pp. 493-500, November 2000. (in Japanese)

7) Okubo, N., Kurita, A., Komatsu, K., and Nakajima, S. : Analytical study on mechanical characteristics of steel-concrete composite girder with grouped stud shear connectors, J. Steel Constr. Eng., JSSC, Vol.9, No.34, pp. 67-75, June 2002. (in Japanese)

8) Okada, J. and Lebet, J.-P. : Strength and behavior of grouped stud connectors, Proc. of the 6th ASCCS Conference, Vol. 1, Los Angeles, USA, pp. 321-328, 2000.

9) Okada, J. and Lebet, J.-P. : Push-out tests for grouped arrangement of stud connectors, Rapport d'essai ICOM 420, EPFL, Lausanne, 2000.

10) Okada, J. and Lebet, J.-P. : Strength and behavior of grouped arrangement of stud connectors, Proc. of the 56th Annual meeting of JSCE, CS2-009, pp. 98-99, 2001. (in Japanese)

11) Okada, J., Yoda, T., and Lebet, J.-P. : Experimental and Analytical Study on Grouped Arrangement of Stud Connectors, Proc. of 5th Japan-German Joint Symposium, Osaka, Japan, pp. 501-509, 2003.

12) Okubo, N., Kurita, A., Komatsu, K., and Ishihara, Y. : Ex- perimental study on static and fatigue characteristics of grouped stud, J. Structural Eng., JSCE, Vol.48A, pp. 1391-1397, March 2002. (in Japanese)

13) Hiragi, H., Matsui, S., and Muto, K. : Development of favorable stud shear connectors to flexible composite actions, $J$. Structural Eng., JSCE, Vol.44A, pp. 1485-1496, March 1998. (in Japanese)

14) Hosaka, T., Hiragi, H., Koeda, Y., Tachibana, Y., and Watanabe, H. : An experimental study on characteristics of shear connectors in composite continuous girders for railway bridges, J. Structural Eng., JSCE, Vol.44A, pp. 1497-1504, March 1998. (in Japanese)

15) TNO Building and Construction Research: DIANA Release 7.2, Delft, Netherlands, 1998.

16) Okada, J. and Yoda, T. : FE-analysis of grouped arrangement of stud connectors, Proc. of the 58th Annual meeting of JSCE, I-490, pp. 979-980, 2003. (in Japanese)

17) European Committee for Standardization: Eurocode 2, Design of concrete structures, 1992.

18) VSM-Normenkommission: VSM 10921, Werkstoffprüfung Zugversuch, 1975.

19) Chen, W.F. : Plasticity in reinforced concrete, Maruzen, 1985. (translated into Japanese)

20) TNO Building and Construction Research: DIANA-7 User's Manual, Nonlinear Analysis, p. 22, 1998.

21) Fujita, Y., Ishimaru, R., Hanai, S., and Suenaga, Y. : Study on internal friction angle and tensile strength of plain concrete, J. Struct. Constr. Eng., AIJ, No.494, pp. 7-14, April 1997. (in Japanese)

22) Dörr, K.: Ein Beitrag zur Berechnung von Stahlbetonscheiben unter besonderer Berücksichtigung des Verbundverhaltens, University of Darmstadt, Germany, 1980.

23) Yamada, M., Pengphon, S., Miki, C., Ichikawa, A., and Irube, T. : Shear strength of slab-anchor and adhesion fixing a non-composite girder bridge's slab, J. Structural Eng., JSCE, Vol.47A, pp. 1161-1168, March 2001. (in Japanese)

24) Akao, S., Kurita, A., and Hiragi, H. : Effect of directions of concrete placing on behavior of headed stud shear connectors in push-out tests, J. Structural Eng./Earthquake Eng., JSCE, No.380/I-7, pp. 311-320, 1987. (in Japanese)

25) Roik, K., Hanswille, G.: Beitrag zur Bestimmung der Tragfäheigkeit von Kopfbolzendübeln, Stahlbau 52, pp. 555-560, 1983.

26) Kuhlmann, U., Breuninger, U.: Zur Tragfäheigkeit von horizontal liegenden Kopfbolzendübeln, Stahlbau 67, pp. 547-554, 1998.

27) Hiragi, H., Muto, K., Matsui, S., and Ishizaki, S. : Influence of the arrangement of the flexible headed stud connectors on the push-out shear behavior, Proc. of the 53rd Annual meeting of JSCE, I-A322, pp. 644-645, 1998. (in Japanese)

(Received August 16, 2005) 